\title{
Functionality of promoter microsatellites of arginine vasopressin receptor 1A (AVPR1A): implications for autism
}

\author{
Katherine E Tansey*, Matthew J Hill, Lynne E Cochrane, Michael Gill, Richard JL Anney and Louise Gallagher
}

\begin{abstract}
Background: Arginine vasopressin (AVP) has been hypothesized to play a role in aetiology of autism based on a demonstrated involvement in the regulation of social behaviours. The arginine vasopressin receptor $1 \mathrm{~A}$ gene (AVPRTA) is widely expressed in the brain and is considered to be a key receptor for regulation of social behaviour. Moreover, genetic variation at AVPRIA has been reported to be associated with autism. Evidence from non-human mammals implicates variation in the 5'-flanking region of AVPR1A in variable gene expression and social behaviour.

Methods: We examined four tagging single nucleotide polymorphisms (SNPs) (rs3803107, rs1042615, rs3741865, rs11174815) and three microsatellites (RS3, RS1 and AVR) at the AVPR1A gene for association in an autism cohort from Ireland. Two 5'-flanking region polymorphisms in the human AVPR1A, RS3 and RS1, were also tested for their effect on relative promoter activity.

Results: The short alleles of RS1 and the SNP rs11174815 show weak association with autism in the Irish population $(P=0.036$ and $P=0.008$, respectively). Both RS1 and RS3 showed differences in relative promoter activity by length. Shorter repeat alleles of RS1 and RS3 decreased relative promoter activity in the human neuroblastoma cell line SH-SY5Y.

Conclusions: These aligning results can be interpreted as a functional route for this association, namely that shorter alleles of RS1 lead to decreased AVPR1A transcription, which may proffer increased susceptibility to the autism phenotype.
\end{abstract}

\section{Background}

The neuropeptide arginine vasopressin (AVP) has been hypothesized to play a role in the aetiology of autism based on a demonstrated involvement in social bonding and in the regulation of a variety of socially relevant behaviours in animal models. Pharmacological experiments in rodents have shown a role for vasopressin in learning and memory, aggression and affiliative behaviours. Increases in AVP are associated with stressful or defensive circumstances and AVP is also involved in aggressive behaviours and pair bonding, mostly in males [1]. AVP regulates male social behaviour not just through higher expression in males but also in steroid-sensitive brain sexual dimorphisms in AVP neurons [1,2]. AVP may therefore influence

\footnotetext{
* Correspondence: katherine.tansey@kcl.ac.uk

Neuropsychiatric Genetics Research Group, Department of Psychiatry, Institute of Molecular Medicine, Trinity College Dublin, Dublin, Ireland
}

sexually dimorphic social behaviours in a range of species [3]. The role of sex hormones on AVP is of interest in the context of autism considering that the ratio of affected males with autism compared to affected females is highly skewed (4:1) [4]. Only one study has examined the relationship between AVP levels and autism; Boso et al. [5] found AVP levels to be higher in plasma from individuals with autism than controls $(P=0.02)$.

AVP acts through binding to G-protein-coupled receptors. One of these receptors, arginine vasopressin receptor 1A (AVPR1A), is widely expressed in the brain. There is considerable evidence to implicate the AVPR $1 A$ gene in social behaviours. AVPR1A-knockout mouse models show impaired social recognition and decreased anxiety behaviours, while overexpression of $A V P R 1 A$ in mice resulted in increased social memory [6,7]. Disruption in AVPR1A expression in the brain has been associated with major behavioural changes [8-11].
C Biomed Central 
In non-human mammals, the variable expression of AVPR1A is implicated in changes in social bonding, parental rearing behaviours and social recognition and memory. Hammock and Young [12] described behavioural differences in voles (genus Microtus) that was related back to the AVP neuropeptide. Prairie voles (Microtus ochrogaster) are socially monogamous through multiple breeding seasons with both the males and females contributing to rearing of the young. These behaviours are not typically seen within closely related species such as the montane vole (Microtus montanus) and meadow vole (Microtus pennsylvanicus). This phenomenon has been attributed to variable expression resulting from a microsatellite marker in the 5'-flanking region of the $A V P R 1 A$ gene in Microtus $[13,14]$.

In humans, the 5 ' region of the gene contains four repeat elements; three promoter repeats ([GT $]_{25}, \mathrm{RS} 1$, ([GATA $]_{14}$ ) and RS3 $\left.\left([\mathrm{CT}]_{4} \mathrm{TT}[\mathrm{CT}]_{8}[\mathrm{GT}]_{24}\right)\right)$ and an intronic repeat (AVR $\left([\mathrm{GT}]_{14}[\mathrm{GA}]_{13}[\mathrm{~A}]_{8}\right)$ ) (see Figure 1) [15]. These polymorphisms, specifically RS1 and RS3 have been studied extensively in terms of their relationship to autism. The data reported thus far has produced inconsistent association with different alleles and markers implicated at this gene. In a sample of 115 autism spectrum disorder (ASD) proband-parent trios, Kim et al. [16] did not observe association for alleles of RS1 or RS3. In a smaller sample of 65 ASD trios, Wassink et al. [17] reported modest association with a shorter allele of the RS1 polymorphism being undertransmitted to probands with autism $(\max P=0.008)$. This was not confirmed in a study of 128 individuals with ASD by Yirmiya et al. [18], where association was observed at the AVR polymorphism $(\max P=0.003)$. More recently, Yang et al. [19] identified association at both RS1 and RS3 in a Korean ASD family-based study. However, the association at the RS1 markers was not consistent with previous findings, which may reflect population differences.

Various studies have linked different lengths of the AVPR1A polymorphisms to behavioural traits in nonclinical samples. Knafo et al. [20] reported that subjects with shorter length RS3 polymorphisms were found to be less generous by the 'dictator game' indicating less altruistic behaviour [20]. Moreover, shorter variants in general were associated with lower levels of $A V P R 1 A$ mRNA in postmortem hippocampus. Recent neuroimaging approaches have also indicated a link between gene expression levels and amygdala activation [21].

Recent studies have highlighted the role of rare de novo inherited copy number variants in the aetiology of autism [22]. However, only rare de novo and inherited variants are established as genetic risk factors, and these account for a small proportion of the total genetic risk [23]. Furthermore, in a recent paper from the International Schizophrenia Consortium, common genetic variants accounted for over $30 \%$ of the genetic risk for schizophrenia [24] and there is no reason to believe this will not be the case for autism as well. The genetic factors influencing the aetiology of autism are likely to be a combination of rare, private and more common variants. The action of which are not likely to be mutually exclusive.

Based on prior evidence suggesting a role for AVP in human and animal social cognition, and prior reports of genetic association between variants in vasopressinrelated genes and autism, we hypothesized that variants in AVPR1A would be associated with autism in our Irish autism sample. We examined the variants RS1, RS3, AVR and four tagging single nucleotide polymorphisms (SNPs) across the gene locus, namely rs3803107, rs1042615, rs3741865 and rs11174815, for association with autism in the Irish autism trio collection. Furthermore, considering the evidence to support a role of 5'-flanking variation in the expression of $A V P R 1 A$ in Microtus, we hypothesised that variation in the $5^{\prime}$ flanking region of the human $A V P R 1 A$ gene at the microsatellites' RS3 and RS1 polymorphisms would influence the relative effects on promoter activity.

\section{Methods}

\section{Sample description}

A total of 177 families, consisting of an affected child and both parents were recruited through schools, parent

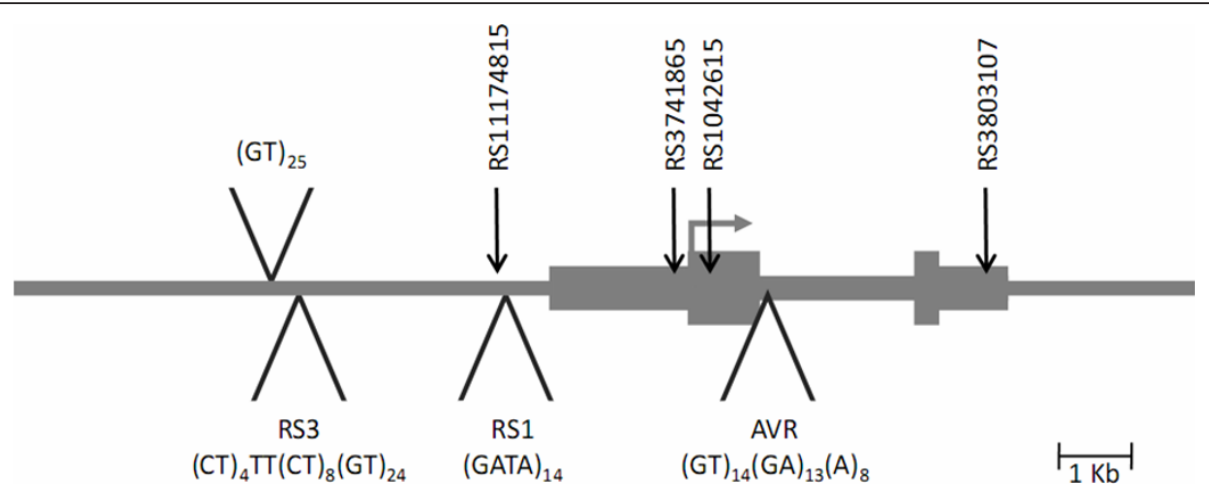

Figure 1 Schematic of the arginine vasopressin receptor $1 \mathrm{~A}$ gene (AVPR1A). 
support groups and clinician referral. The male to female ratio was 4.68:1. Autism diagnoses were confirmed using Autism Diagnostic Interview - Revised (ADI-R) [25] and the Autism Diagnostic Observation Schedule - Generic (ADOS-G) [26]. IQ and Vineland Adaptive Behaviour Score (VABS) [27] were evaluated to establish a distribution of functioning within the sample. Individuals with known medical causes of autism (for example, tuberous sclerosis, extreme prematurity, congenital rubella) were excluded. Subjects met the ADI-R criteria for autism, and the ADOS-G criteria for autism or ASD. All individuals had an IQ $>35$ or a mental age (as defined by the VABS) $>18$ months. Ethical approval was obtained from the Health Services Executive Linn Dara Child and Adolescent Psychiatry Ethics Committee, Ireland. DNA was extracted from blood or buccal swabs using the phenol/chloroform extraction method.

\section{Genotyping}

Using the HapMap CEPH data, four SNPs in the $A V P R 1 A$ locus were identified using the tagger function of Haploview [28]. SNPs were selected using pairwise tagging with an $\mathrm{r}^{2}$ threshold of 0.8 with an additional 2000 base pairs taken $5^{\prime}$ and $3^{\prime}$ of the gene transcript. SNP genotyping was performed by a commercial genotyping company, KBiosciences (http://www.kbioscience. co.uk/) using Kaspar assays. Three additional microsatellite polymorphisms (RS1, RS3, and AVR) at the AVPR1A gene locus were also genotyped. RS1: forward (fluorescent) 5'-AGG GAC TGG TTC TAC AAT CTG C-3'; reverse 5'-ACC TCT CAA GTT ATG TTG GTG G-3'. RS3: forward (fluorescent) 5'-CCT GTA GAG ATG TAA GTC CT-3'; reverse 5'-TCT GGA AGA GACT
TAG ATG G-3'. AVR: forward (fluorescent) 5'-ATC CCA TGT CCG TCT GGA C-3'; reverse 5'-AGT GTT CCT CCA AGG TGC G-3' $[15,18]$. Each reaction contained $0.5 \mathrm{mM}$ primer. The sample was initially heated for $10 \mathrm{~min}$ at $95^{\circ} \mathrm{C}$ followed by 30 cycles of $95^{\circ} \mathrm{C}(30 \mathrm{~s})$, $55^{\circ} \mathrm{C}(30 \mathrm{~s}), 72^{\circ} \mathrm{C}(40 \mathrm{~s})$ and a final extension step of $72^{\circ} \mathrm{C}$ for $10 \mathrm{~min}$. An ABI 3130XL Genetic Analyzer (Applied Biosystems, Foster City, CA, USA) was used to determine the length of each PCR product. Samples were analysed using Genemapper v2.7 (Applied Biosystems).

\section{Construction of the reporter vectors}

DNA samples of individuals homozygous for the RS3 variants (allele 325 and allele 339) and RS1 (allele 306 and 322) were selected from CEPH HapMap individuals. PCR amplification of a DNA fragment containing allele 325 and allele 339 of RS3 were amplified using primers: forward 5'-CCT GTA GAG ATG TAA GTG CT-3'; reverse 5' CTC GAG TCT GGA AGA GAC TTA GAT GG-3'. For RS1, allele 306 and allele 322 were amplified using primers: forward 5'-AGG GAC TGG TTC TAC AAT CTG C-3'; reverse 5'-CTC GAG ACC TCT CAA GTT ATG TTG GTG G-3'. Amplified sequences were cloned into the pGEM-T vector (Promega, Southampton, UK). The RS3 and RS1 alleles were subcloned into the $S a c I$ and XhoI site in the pGL3 control vector (Promega). The amplified promoter fragments do not contain the core promoter elements of AVPR1A. Therefore, the pGL3 control vector as opposed to the pGL3 Basic vector was used to examine the modulating influence of these elements as 5'-flanking polymorphism through an SV40 promoter. Vector maps of the tested constructs are shown in Figure 2. Sequence analysis using a BigDye
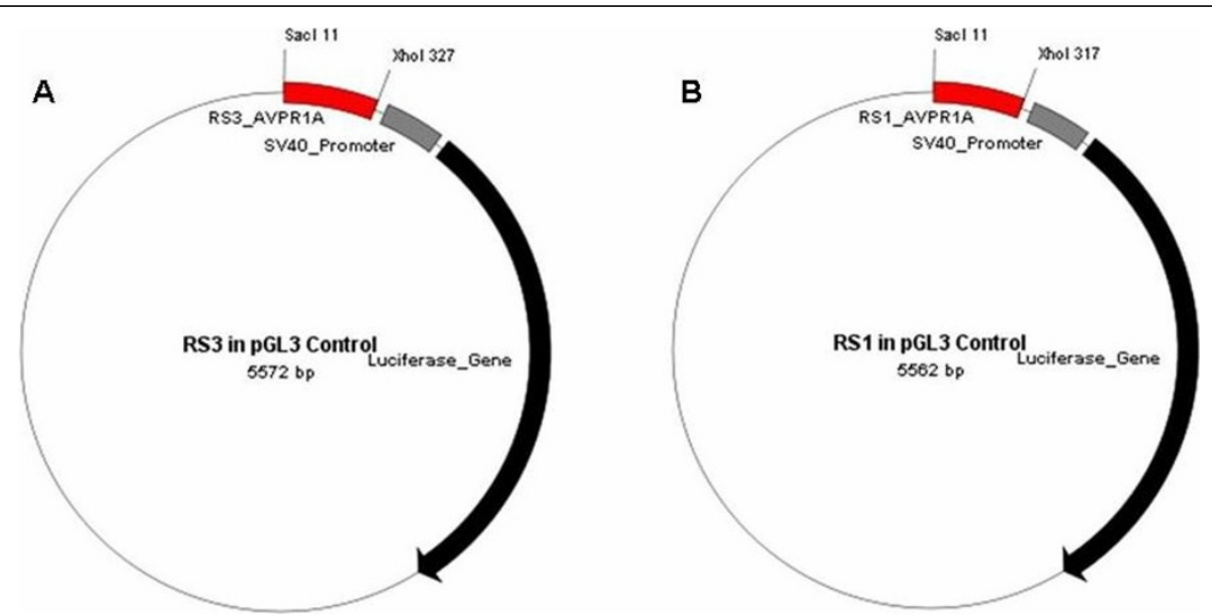

Figure 2 Vector maps of the RS3 (a) and RS1 (b) alleles subcloned into pGL3 control vector. Inserts were chosen based upon length of polymorphism, two per polymorphism. The restriction sites used for both RS3 and RS1 were Sacl and Xhol, located before the viral promoter SV40. 
Terminator v3.1 Cycle Sequencing Kit (ABI PRISM, Applied Biosystems) was performed to confirm the fidelity and orientation of all inserts.

\section{Cell culture and transfection}

The human neuroblastoma cell line SH-SY5Y, were maintained in RPMI 1640 containing 10\% foetal bovine serum (FBS) at $37^{\circ} \mathrm{C}$ and $5 \% \mathrm{CO}_{2}$. Transfections were performed in triplicate a minimum of three times using Lipofectamine 2000 reagent (Invitrogen, Carlsbad, CA, USA) according to the manufacturer's instructions.

\section{Luciferase assay}

Luciferase assays were performed using the dual-glow luciferase system (Promega) according to the manufactures' instructions. Luminescence was measured on a Victor plate reader (PerkinElmer, Boston, MA, USA). Transfection efficiency was corrected for by normalising data relative to the cotransfected renilla luciferase pRLcytomegalovirus (CMV) control vector (Promega). For the RS3 and RS1 constructs, $100 \mathrm{ng}$ of test constructs were cotransfected with $500 \mathrm{ng}$ pGL3 control vector. Expression was reported as relative to the pGL3 control vector.

\section{Statistical analyses}

Transmission disequilibrium test (TDT) for the three microsatellites from $A V P R 1 A$ were analysed in UNPHASED [29]. Each allele is tested independently for transmission disequilibrium. Research previously undertaken in voles demonstrated the repeat length of the polymorphism modified gene expression, transcriptional pattern in the brain and social behaviours [14]. Therefore, we decided to test for association between the length of polymorphic repeat and autism. Alleles were grouped in 'long' alleles and 'short' alleles for RS1, RS3 and AVR polymorphisms. Nomenclature of alleles for RS1 and RS3 can be found in Yirmiya et al. [18]. For RS3, 'long' refers to allele 327 and all repeats longer than 327 and 'short' refers to allele 325 and all repeats shorter than allele 325 consistent with the previously published study of Knafo et al. [20]. For RS1, 'long' consists of allele 314 and all repeats larger than allele 314 and 'short' consists of allele 310 and all repeats shorter than allele 310. For AVR, 'short' includes allele 213 and all repeats shorter than allele 213, while 'long' includes allele 215 and all repeats larger than allele 215. A similar procedure has been applied to other complex polymorphism, such as the nitric oxide synthase 1 (NOS1) ex1f- variable number tandem repeat (VNTR) [30-33].

Hardy-Weinberg equilibrium and TDT analyses for SNP markers were performed using PLINK [34]. TDT for dichotomised microsatellites (long versus short) was also performed using PLINK. No Mendelian incompatibilities were detected and all variants were found to be in HardyWeinberg equilibrium $(P>0.01)$ in the parents. Permutation procedures were performed in PLINK using the mperm function $(n=1000)$. Haplotypes were defined using Gabriel's confidence intervals and tested for association using permutation in Haploview $(n=1000)[28,35]$.

The statistical significance of differences in relative gene reporter activity was examined using two-tailed Student's $t$ test in Stata v. 10 (StataCorp, College Station, TX, USA).

\section{Power calculation}

In the Irish autism sample $(n=177)$ at minor allele frequencies of 0.20 , there was greater than $80 \%$ power to observe an effect of odds ratio (OR) approximately 1.35 at an uncorrected $P=0.05$ level. This calculation considers a modest effect size and also no linkage disequilibrium between the test and causative marker.

\section{Results}

\section{Genetic association analyses}

Of the seven markers (four SNPs and three microsatellite markers), only one showed a significant association with autism in the Irish autism sample (rs11174815, nominal $P=0.008$ ). Dichotomisation of the RS1 allele revealed a weak association of the RS1 short allele and autism (nominal $P=0.036$; odds ratio (OR) $1.44 ; 95 \%$ confidence interval 1.02 to 2.04) (Tables 1 and 2). No significant haplotype associations were observed (data not shown).

\section{Gene reporter assays for the RS1 and RS3 polymorphism of AVPR1A}

Differential activity was observed for alleles of both the RS1 and RS3 variants when expressed as a luciferase construct in the pGL3 control vector. In SH-SY5Y cells, the long repeat of the RS1 polymorphism showed 2.7 times higher relative activity compared to the shorter length repeat ( $P=0.0005$, Student's $t$ test) (Figure 3 ). Similarly, for the long repeat of the RS3 variant was 1.4 times more active than the short-repeat allele $(P=$ 0.0081, Student's $t$ test) (Figure 3).

\section{Discussion}

In the current work we present the results of genetic investigations of the $A V P R 1 A$ gene in an Irish autism sample. We followed association analysis with investigations to examine the role of promoter region polymorphisms, RS1 and RS3, on relative promoter activity.

Overall, we observed a single association with AVPR1A in the Irish autism trio collection (rs11174815, corrected $P=0.01$ ). Due to the very low minor allele frequency (minor allele frequency $(\mathrm{MAF})=0.015)$ and lack of observations for transmissions of the A allele, it 
Table 1 Genotype association results using UNPHASED for multiallelic markers and PLINK for dichotomous markers

\begin{tabular}{|c|c|c|c|c|c|c|}
\hline Marker & Allele & Frequency & $\mathrm{T}$ & NT & $\chi^{2}$ & $P$ value \\
\hline \multirow[t]{17}{*}{ RS3 } & 305 & 0.001 & 0 & 1 & 1.00 & 0.32 \\
\hline & 311 & 0.005 & 2 & 1 & 0.33 & 0.56 \\
\hline & 319 & 0.001 & 0 & 1 & 1.00 & 0.32 \\
\hline & 321 & 0.008 & 3 & 1 & 1.00 & 0.32 \\
\hline & 323 & 0.058 & 19 & 16 & 0.26 & 0.61 \\
\hline & 325 & 0.102 & 31 & 24 & 0.89 & 0.35 \\
\hline & 327 & 0.214 & 45 & 36 & 1.00 & 0.32 \\
\hline & 329 & 0.210 & 43 & 54 & 1.25 & 0.26 \\
\hline & 331 & 0.099 & 25 & 26 & 0.02 & 0.89 \\
\hline & 333 & 0.167 & 44 & 42 & 0.05 & 0.83 \\
\hline & 335 & 0.026 & 6 & 11 & 1.47 & 0.23 \\
\hline & 337 & 0.014 & 4 & 2 & 0.67 & 0.41 \\
\hline & 339 & 0.059 & 14 & 20 & 1.06 & 0.30 \\
\hline & 341 & 0.015 & 4 & 5 & 0.11 & 0.74 \\
\hline & 343 & 0.017 & 5 & 6 & 0.09 & 0.76 \\
\hline & 345 & 0.004 & 2 & 1 & 0.33 & 0.56 \\
\hline & Short & 0.390 & 86 & 65 & 2.92 & 0.09 \\
\hline RS11174815 & $A$ & 0.015 & 0 & 7 & 7.00 & $0.008^{a} 0$ \\
\hline \multirow[t]{9}{*}{$\overline{\mathrm{RS} 1}$} & 302 & 0.004 & 0 & 3 & 3.00 & 0.08 \\
\hline & 306 & 0.161 & 39 & 31 & 0.91 & 0.34 \\
\hline & 310 & 0.448 & 67 & 52 & 1.89 & 0.17 \\
\hline & 314 & 0.193 & 33 & 46 & 2.14 & 0.14 \\
\hline & 318 & 0.079 & 20 & 26 & 0.78 & 0.38 \\
\hline & 322 & 0.096 & 24 & 30 & 0.67 & 0.41 \\
\hline & 330 & 0.014 & 5 & 1 & 2.67 & 0.10 \\
\hline & 334 & 0.005 & 2 & 1 & 0.33 & 0.56 \\
\hline & Short & 0.518 & 78 & 54 & 4.36 & $0.036^{b}$ \\
\hline RS3741865 & $\mathrm{T}$ & 0.008 & 2 & 1 & 0.33 & 0.56 \\
\hline RS1042615 & $\mathrm{T}$ & 0.436 & 55 & 58 & 0.08 & 0.78 \\
\hline \multirow[t]{10}{*}{ AVR } & 204 & 0.002 & 1 & 0 & 1.00 & 0.32 \\
\hline & 208 & 0.010 & 2 & 0 & 2.00 & 0.16 \\
\hline & 210 & 0.108 & 16 & 21 & 0.68 & 0.41 \\
\hline & 212 & 0.272 & 43 & 41 & 0.05 & 0.83 \\
\hline & 214 & 0.461 & 51 & 48 & 0.09 & 0.76 \\
\hline & 216 & 0.040 & 10 & 10 & 0.00 & 1.00 \\
\hline & 218 & 0.006 & 0 & 1 & 1.00 & 0.32 \\
\hline & 220 & 0.064 & 10 & 11 & 0.05 & 0.83 \\
\hline & 222 & 0.001 & 0 & 1 & 1.00 & 0.32 \\
\hline & Short & 0.411 & 79 & 79 & 0.00 & 1.00 \\
\hline RS3803107 & $\mathrm{T}$ & 0.178 & 32 & 30 & 0.06 & 0.79 \\
\hline
\end{tabular}

$\mathrm{T}=$ transmitted, NT = non-transmitted.

Associations at the suggestive $\alpha$ level 0.05 are shown in bold text.

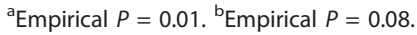

Table 2 Multimarker transmission disequilibrium test (TDT) for the microsatellite markers RS3, RS1 and AVR reporting the likelihood ratio statistic (LRS), degrees of freedom (df) and global $P$ value from UNPHASED

\begin{tabular}{llll}
\hline Marker & LRS & df & $\boldsymbol{P}$ value \\
\hline RS3 & 10.76 & 15 & 0.769 \\
\hline RS1 & 12.22 & 7 & 0.094 \\
\hline AVR & 8.085 & 8 & 0.425 \\
\hline
\end{tabular}

is difficult to conclude the relationship between this marker and autism in the Irish autism sample from our study. Furthermore, a weak association signal was seen between the dichotomised RS1 polymorphism and individuals with autism in the Irish sample. The short alleles were overtransmitted in individuals with autism.

We performed an experimental examination of the effect of allele length of the RS1 and RS3 polymorphism on relative promoter activity in the luciferase gene reporter assay. For the RS1 variant we observed the shorter allele to show lower relative promoter activity. Previous studies have reported shorter RS1 polymorphisms show more activity in the left amygdala in a nonclinical sample [36]. Excessive amygdala activation during social interaction has been reported to be associated with increase anxiety and eventually social withdrawal [37]. These aligning results suggest shorter alleles of RS1 result in lower relative promoter activity and possibly reduced transcription of $A V P R 1 A$, increasing amygdala activity leading to social withdrawal.

Shorter alleles of the RS3 polymorphism also lead to lower relative promoter activity in the luciferase gene reporter assay. While the RS3 polymorphism was not shown to be associated with autism in the Irish autism sample, it has been shown previously to be associated with individuals with autism $[17,18,38]$. Knafo et al. [20] reported individuals with shorter variants of the RS3 polymorphism have lower hippocampal AVPR1A mRNA and shorter alleles lead to less prosocial behaviours than longer alleles. Potentially, shorter alleles of the RS3 polymorphism, which show lower relative promoter activity, lead to reduced levels of $A V P R 1 A$ mRNA and lower levels of AVPR1A in cells. Decreased levels of AVPR1A potentially could result in less altruistic behaviours (Table 3).

In a recent study, the human RS1 polymorphism showed no differences in COS7 cells [39]. Furthermore, Hong et al. [39] repeated the experiment in the PC12 cell line with no difference shown; however expression levels were extremely low indicating a potential weak promoter in AVPR1A. The difference in results between this study and ours is not surprising given recent 
A

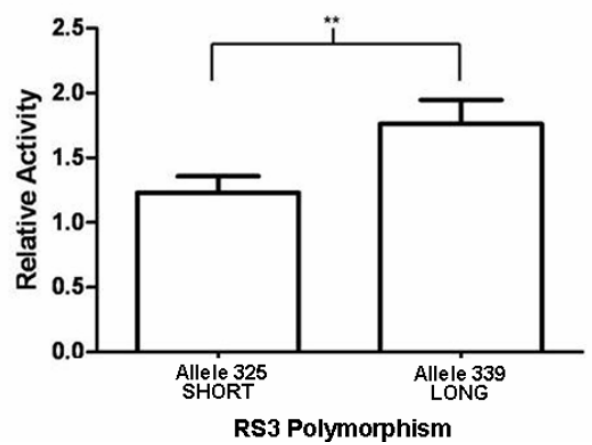

B

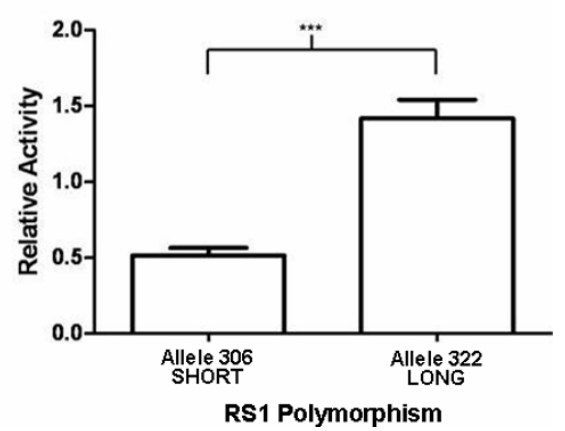

Figure 3 Relative activity of the RS3 (a) and RS1 (b) polymorphisms constructs in the neuronal SH-SY5Y cell line. (a) Longer length repeat of the RS3 polymorphism of the arginine vasopressin receptor $1 \mathrm{~A}$ gene (AVPR1A) showed higher relative activity compared to the shorter length repeat of RS3 in SH-SY5Y cell lines $(P=0.0081$, Student's $t$ test). (b) Longer length repeat of the RS1 polymorphism of AVPRTA showed higher relative activity compared to the shorter length repeat $\left(P=0.0005\right.$, Student's $t$ test). ${ }^{* *} P<0.01 ;{ }^{* *} P<0.001$. The graph shows the mean of the data and standard error of the mean.

Table 3 Results from previous studies on the arginine vasopressin receptor 1A gene (AVPR1A) RS3 polymorphism demonstrating the functionality of this region

\begin{tabular}{lllll}
\hline $\begin{array}{l}\text { AVPR1A RS3 repeat } \\
\text { length classification }\end{array}$ & $\begin{array}{l}\text { Postmortem } \\
\text { hippocampal mRNA } \\
\text { levels [20] }\end{array}$ & $\begin{array}{l}\text { Prepulse } \\
\text { inhibition } \\
\text { [45] }\end{array}$ & $\begin{array}{l}\text { Dictator game and real } \\
\text { money allocations [20] }\end{array}$ & $\begin{array}{l}\text { Amygdala activation to } \\
\text { face recognition [21] }\end{array}$ \\
\hline Short & Down & Down & Down & Down \\
\hline Long & Up & Up (males) & Up & Up \\
\hline
\end{tabular}

Up/down indicate the direction of effect. Adapted from Levin et al. [45].

evidence that cis-acting variation differs between tissue and cell types [40-44]. Our study examines the enhancer effects of RS1 and RS3 in an appropriate and relevant cell type for consideration in the aetiology of autism, a neurological disorder. In the study undertaken here, RS1 and RS3 are examined as enhancers modulating a viral promoter SV40 instead of its own natural promoter. Gene reporter systems do not take into account the genomic or chromatin context of the elements tested, however it is encouraging that our data agree with postmortem mRNA levels as shown in Knafo et al. [20], although additional studies are warranted. While the genomic environment tested was an artificial construction without the use of the endogenous promoter, these data do indicate that the repeat elements influence the relative activity of a core promoter in neuronal cells.

\section{Conclusions}

The results from both RS3 and RS1 luciferase gene reporter assays are intriguing, with potentially shorter variants of both RS3 and RS1 leading to decreases in AVPR1A mRNA. Our results align with the study undertaken on the Microtus microsatellites, which showed decreased microsatellite length contributes to decreased sociability [13]. This suggests a potential conservation of function across species highlighting the importance of these polymorphisms. However, the functionality of both polymorphisms in our study complicates any conclusions. A limitation of the gene reporter approach is the removal of additional regulatory mechanisms, which may affect the DNA region of interest, and in these particular polymorphisms, how these polymorphisms may interact with each other in the regulation of AVPR1A transcription. Our haplotype analysis between the dichotomised alleles of RS1 and RS3 showed no association in the Irish sample. Rigorous meta-analysis is currently not possible due to the use of different genotyping methodologies [45]. We have used the same genotyping primers as the Knafo et al. [20], Meyer-Lindenberg et al. [21] and Levin et al. [45] allowing us to draw conclusions easily across these studies. Future work examining the regulatory relationship between these two polymorphisms will be essential for better understanding of how they influence in vivo transcription of $A V P R 1 A$ and ultimately how they potentially play a role in the aetiology of autism.

\section{Acknowledgements}

We thank the families who took part in this study for their support and cooperation. Family collection in Ireland and data analysis was supported by grants from the Health Research Board, Ireland, The Wellcome Trust, UK, and the National Alliance for Autism Research, USA. 


\section{Authors' contributions}

KET and RJLA wrote the manuscript. KET performed the laboratory work and data analysis undertaken in this manuscript. KET, MJH and RJLA conceived the experiment. MJH and RJLA supervised design, laboratory methods, and data analysis. MJH, LEC, MG and LG aided in manuscript preparation. MG, LG and RJLA were involved in the supervision and conception of the experiment.

\section{Competing interests}

The authors declare that they have no competing interests.

Received: 7 September 2010 Accepted: 31 March 2011

Published: 31 March 2011

\section{References}

1. Goodson JL, Bass AH: Social behavior functions and related anatomical characteristics of vasotocin/vasopressin systems in vertebrates. Brain Res Brain Res Rev 2001, 35:246-265.

2. Bales KL, Plotsky PM, Young LJ, Lim MM, Grotte N, Ferrer E, Carter CS: Neonatal oxytocin manipulations have long-lasting, sexually dimorphic effects on vasopressin receptors. Neuroscience 2007, 144:38-45.

3. Ferris WF, Naran NH, Crowther NJ, Rheeder P, van der Merwe L, Chetty N: The relationship between insulin sensitivity and serum adiponectin levels in three population groups. Horm Metab Res 2005, 37:695-701.

4. Chakrabarti S, Fombonne E: Pervasive developmental disorders in preschool children: confirmation of high prevalence. Am J Psychiatry 2005, 162:1133-1141.

5. Boso M, Emanuele E, Politi P, Pace A, Arra M, Ucelli di Nemi S, Barale F: Reduced plasma apelin levels in patients with autistic spectrum disorder. Arch Med Res 2007, 38:70-74.

6. Bielsky IF, Hu SB, Young LJ: Sexual dimorphism in the vasopressin system lack of an altered behavioral phenotype in female V1a receptor knockout mice. Behav Brain Res 2005, 164:132-136.

7. Bielsky IF, Hu SB, Szegda KL, Westphal H, Young L: Profound impairment in social recognition and reduction in anxiety-like behavior in vasopressin V1a receptor knockout mice. Neuropsychopharmacology 2004, 29:483-493.

8. Lim MM, Bielsky IF, Young LJ: Neuropeptides and the social brain: potential rodent models of autism. Int J Dev Neurosci 2005, 23:235-243.

9. Young LJ, Toloczko D, Insel TR: Localization of vasopressin (V1a) receptor binding and mRNA in the rhesus monkey brain. J Neuroendocrinol 1999, 11:291-297.

10. Insel TR, Wang ZX, Ferris CF: Patterns of brain vasopressin receptor distribution associated with social organization in microtine rodents. $J$ Neurosci 1994, 14:5381-5392.

11. Young $L$, Winslow JT, Nilsen $R$, Insel TR: Species differences in V1a receptor gene expression in monogamous and nonmonogamous voles: behavioral consequences. Behav Neurosci 1997, 111:599-605.

12. Hammock EA, Young $\amalg$ : Variation in the vasopressin V1a receptor promoter and expression: implications for inter- and intraspecific variation in social behaviour. Eur J Neurosci 2002, 16:399-402.

13. Hammock EA, Lim MM, Nair HP, Young LJ: Association of vasopressin 1a receptor levels with a regulatory microsatellite and behavior. Genes Brain Behav 2005, 4:289-301.

14. Hammock EA, Young $\amalg$ : Microsatellite instability generates diversity in brain and sociobehavioral traits. Science 2005, 308:1630-1634.

15. Thibonnier M, Graves MK, Wagner MS, Chatelain N, Soubrier F, Corvol P, Willard HF, Jeunemaitre X: Study of V(1)-vascular vasopressin receptor gene microsatellite polymorphisms in human essential hypertension. $J$ Mol Cell Cardiol 2000, 32:557-564.

16. Kim SJ, Young LJ, Gonen D, Veenstra-VanderWeele J, Courchesne R, Courchesne E, Lord C, Leventhal BL, Cook EH Jr, Insel TR: Transmission disequilibrium testing of arginine vasopressin receptor 1A (AVPR1A) polymorphisms in autism. Mol Psychiatry 2002, 7:503-507.

17. Wassink TH, Piven J, Vieland VJ, Pietila J, Goedken RJ, Folstein SE, Sheffield VC: Examination of AVPR1a as an autism susceptibility gene. Mol Psychiatry 2004, 9:968-972.

18. Yirmiya N, Rosenberg C, Levi S, Salomon S, Shulman C, Nemanov L, Dina C, Ebstein RP: Association between the arginine vasopressin 1a receptor (AVPR1a) gene and autism in a family-based study: mediation by socialization skills. Mol Psychiatry 2006, 11:488-494.
19. Yang SY, Cho SC, Yoo HJ, Cho IH, Park M, Yoe J, Kim SA: Family-based association study of microsatellites in the $5^{\prime}$ flanking region of AVPR1A with autism spectrum disorder in the Korean population. Psychiatry Res 2010, 178:199-201.

20. Knafo A, Israel S, Darvasi A, Bachner-Melman R, Uzefovsky F, Cohen L, Feldman E, Lerer E, Laiba E, Raz Y, Nemanov L, Gritsenko I, Dina C, Agam G, Dean B, Bornstein G, Ebstein RP: Individual differences in allocation of funds in the dictator game associated with length of the arginine vasopressin 1a receptor RS3 promoter region and correlation between RS3 length and hippocampal mRNA. Genes Brain Behav 2008, 7:266-275.

21. Meyer-Lindenberg A, Kolachana B, Gold B, Olsh A, Nicodemus KK, Mattay V, Dean $M$, Weinberger DR: Genetic variants in AVPR1A linked to autism predict amygdala activation and personality traits in healthy humans. Mol Psychiatry 2009, 14:968-975

22. Pinto D, Pagnamenta AT, Klei L, Anney R, Merico D, Regan R, Conroy J, Magalhaes TR, Correia C, Abrahams BS, Almeida J, Bacchelli E, Bader GD, Bailey AJ, Baird G, Battaglia A, Berney T, Bolshakova N, Bölte S, Bolton PF, Bourgeron T, Brennan S, Brian J, Bryson SE, Carson AR, Casallo G, Casey J, Chung $\mathrm{BH}$, Cochrane $\mathrm{L}$, Corsello $\mathrm{C}$, et al: Functional impact of global rare copy number variation in autism spectrum disorders. Nature 466:368-372.

23. Anney R, Klei L, Pinto D, Regan R, Conroy J, Magalhaes TR, Correia C, Abrahams BS, Sykes N, Pagnamenta AT, Almeida J, Bacchelli E, Bailey AJ, Baird G, Battaglia A, Berney T, Bolshakova N, Bölte S, Bolton PF, Bourgeron T, Brennan S, Brian J, Carson AR, Casallo G, Casey J, Chu SH, Cochrane L, Corsello C, Crawford EL, Crossett A, et al: A genome-wide scan for common alleles affecting risk for autism. Hum Mol Genet 19:4072-4082.

24. Purcell SM, Wray NR, Stone $J$, Visscher PM, O'Donovan MC, Sullivan PF, Sklar P: Common polygenic variation contributes to risk of schizophrenia and bipolar disorder. Nature 2009, 460:748-752.

25. Lord C, Rutter M, Le Couteur A: Autism Diagnostic Interview-Revised: a revised version of a diagnostic interview for caregivers of individuals with possible pervasive developmental disorders. J Autism Dev Disord 1994, 24:659-685.

26. Lord C, Risi S, Lambrecht L, Cook EH Jr, Leventhal BL, DiLavore PC, Pickles A, Rutter M: The autism diagnostic observation schedule-generic: a standard measure of social and communication deficits associated with the spectrum of autism. J Autism Dev Disord 2000, 30:205-223.

27. Sparrow SS, Cicchetti DV: Diagnostic uses of the Vineland Adaptive Behavior Scales. J Pediatr Psychol 1985, 10:215-225

28. Barrett JC, Fry B, Maller J, Daly MJ: Haploview: analysis and visualization of LD and haplotype maps. Bioinformatics 2005, 21:263-265.

29. Dudbridge F: Likelihood-based association analysis for nuclear families and unrelated subjects with missing genotype data. Hum Hered 2008, 66:87-98.

30. Galimberti D, Scarpini E, Venturelli E, Strobel A, Herterich S, Fenoglio C, Guidi I, Scalabrini D, Cortini F, Bresolin N, Lesch KP, Reif A: Association of a NOS1 promoter repeat with Alzheimer's disease. Neurobiol Aging 2008, 29:1359-1365.

31. Reif A, Herterich $S$, Strobel A, Ehlis AC, Saur D, Jacob CP, Wienker T, Topner T, Fritzen S, Walter U, Schmitt A, Fallgatter AJ, Lesch KP: A neuronal nitric oxide synthase (NOS-I) haplotype associated with schizophrenia modifies prefrontal cortex function. Mol Psychiatry 2006, 11:286-300.

32. Reif A, Jacob CP, Rujescu D, Herterich S, Lang S, Gutknecht L, Baehne CG, Strobel A, Freitag CM, Giegling I, Romanos M, Hartmann A, Rösler M, Renner TJ, Fallgatter AJ, Retz W, Ehlis AC, Lesch KP: Influence of functional variant of neuronal nitric oxide synthase on impulsive behaviors in humans. Arch Gen Psychiatry 2009, 66:41-50.

33. Reif A, Kiive E, Kurrikoff $T$, Paaver M, Herterich $S$, Konstabel $K$, Tulviste $T$, Lesch KP, Harro J: A functional NOS1 promoter polymorphism interacts with adverse environment on functional and dysfunctional impulsivity. Psychopharmacology (Berl) 2010.

34. Purcell $S$, Neale $B$, Todd-Brown $K$, Thomas L, Ferreira MA, Bender D, Maller J, Sklar P, de Bakker PI, Daly MJ, Sham PC: PLINK: a tool set for wholegenome association and population-based linkage analyses. Am J Hum Genet 2007, 81:559-575.

35. Gabriel SB, Schaffner SF, Nguyen H, Moore JM, Roy J, Blumenstiel B, Higgins J, DeFelice M, Lochner A, Faggart M, Liu-Cordero SN, Rotimi C, Adeyemo A, Cooper R, Ward R, Lander ES, Daly MJ, Altshuler D: The structure of haplotype blocks in the human genome. Science 2002, 296:2225-2229. 
36. Meyer-Lindenberg A, Kolachana B, Gold B, Olsh A, Nicodemus KK, Mattay V, Dean M, Weinberger DR: Genetic variants in AVPR1A linked to autism predict amygdala activation and personality traits in healthy humans. Mol Psychiatry 2009, 14:968-75.

37. Stein MB, Goldin PR, Sareen J, Zorrilla LT, Brown GG: Increased amygdala activation to angry and contemptuous faces in generalized social phobia. Arch Gen Psychiatry 2002, 59:1027-1034.

38. Israel S, Lerer E, Shalev I, Uzefovsky F, Reibold M, Bachner-Melman R, Granot R, Bornstein G, Knafo A, Yirmiya N, Ebstein RP: Molecular genetic studies of the arginine vasopressin 1a receptor (AVPR1a) and the oxytocin receptor (OXTR) in human behaviour: from autism to altruism with some notes in between. Prog Brain Res 2008, 170:435-449.

39. Hong KW, Matsukawa R, Hirata $Y$, Hayasaka I, Murayama Y, Ito S, InoueMurayama M: Allele distribution and effect on reporter gene expression of vasopressin receptor gene (AVPR1a)-linked VNTR in primates. J Neural Transm 2009, 116:535-538.

40. Cowles CR, Hirschhorn JN, Altshuler D, Lander ES: Detection of regulatory variation in mouse genes. Nat Genet 2002, 32:432-437.

41. Koch O, Kwiatkowski DP, Udalova IA: Context-specific functional effects of IFNGR1 promoter polymorphism. Hum Mol Genet 2006, 15:1475-1481.

42. Sun C, Southard C, Witonsky DB, Olopade OI, Di Rienzo A: Allelic imbalance (AI) identifies novel tissue-specific cis-regulatory variation for human UGT2B15. Hum Mutat 31:99-107.

43. Wilkins JM, Southam L, Price AJ, Mustafa Z, Carr A, Loughlin J: Extreme context specificity in differential allelic expression. Hum Mol Genet 2007, 16:537-546.

44. Zhang K, Li JB, Gao Y, Egli D, Xie B, Deng J, Li Z, Lee JH, Aach J, Leproust EM, Eggan K, Church GM: Digital RNA allelotyping reveals tissuespecific and allele-specific gene expression in human. Nat Methods 2009, 6:613-618.

45. Levin R, Heresco-Levy U, Bachner-Melman R, Israel S, Shalev I, Ebstein RP: Association between arginine vasopressin 1a receptor (AVPR1a) promoter region polymorphisms and prepulse inhibition. Psychoneuroendocrinology 2009, 34:901-908.

doi:10.1186/2040-2392-2-3

Cite this article as: Tansey et al.: Functionality of promoter microsatellites of arginine vasopressin receptor 1A (AVPR1A): implications for autism. Molecular Autism 2011 2:3.

\section{Submit your next manuscript to BioMed Central and take full advantage of:}

- Convenient online submission

- Thorough peer review

- No space constraints or color figure charges

- Immediate publication on acceptance

- Inclusion in PubMed, CAS, Scopus and Google Scholar

- Research which is freely available for redistribution

Submit your manuscript at www.biomedcentral.com/submit
Biomed Central 